Article

\title{
Radiometric Correction and 3D Integration of Long-Range Ground-Based Hyperspectral Imagery for Mineral Exploration of Vertical Outcrops
}

\author{
Sandra Lorenz ${ }^{1, *}$, Sara Salehi ${ }^{2,3}$, Moritz Kirsch ${ }^{1}$, Robert Zimmermann ${ }^{1}{ }^{(\mathbb{D}}$, Gabriel Unger ${ }^{1}$, \\ Erik Vest Sørensen ${ }^{2}$ (i) and Richard Gloaguen ${ }^{1}$ (i) \\ 1 Helmholtz-Zentrum Dresden-Rossendorf, Helmholtz Institute Freiberg for Resource Technology, \\ Division "Exploration Technology", Chemnitzer Straße 40, 09599 Freiberg, Germany; \\ m.kirsch@hzdr.de (M.K.); r.zimmermann@hzdr.de (R.Z.); g.unger@hzdr.de (G.U.); r.gloaguen@hzdr.de (R.G.) \\ 2 Department of Petrology and Economic Geology, Geological Survey of Denmark and Greenland, \\ 1350 Copenhagen K, Denmark; ssal@geus.dk (S.S.); evs@geus.dk (E.V.S.) \\ 3 Department of Geosciences and Natural Resource Management, University of Copenhagen, \\ 1165 Copenhagen K, Denmark \\ * Correspondence: s.lorenz@hzdr.de; Tel.: +49-351-260-4487
}

Received: 22 December 2017; Accepted: 24 January 2018; Published: 26 January 2018

\begin{abstract}
Recently, ground-based hyperspectral imaging has come to the fore, supporting the arduous task of mapping near-vertical, difficult-to-access geological outcrops. The application of outcrop sensing within a range of one to several hundred metres, including geometric corrections and integration with accurate terrestrial laser scanning models, is already developing rapidly. However, there are few studies dealing with ground-based imaging of distant targets (i.e., in the range of several kilometres) such as mountain ridges, cliffs, and pit walls. In particular, the extreme influence of atmospheric effects and topography-induced illumination differences have remained an unmet challenge on the spectral data. These effects cannot be corrected by means of common correction tools for nadir satellite or airborne data. Thus, this article presents an adapted workflow to overcome the challenges of long-range outcrop sensing, including straightforward atmospheric and topographic corrections. Using two datasets with different characteristics, we demonstrate the application of the workflow and highlight the importance of the presented corrections for a reliable geological interpretation. The achieved spectral mapping products are integrated with $3 \mathrm{D}$ photogrammetric data to create large-scale now-called "hyperclouds", i.e., geometrically correct representations of the hyperspectral datacube. The presented workflow opens up a new range of application possibilities of hyperspectral imagery by significantly enlarging the scale of ground-based measurements.
\end{abstract}

Keywords: hyperspectral; topographic correction; atmospheric correction; radiometric correction; long-range; long-distance; Structure from Motion (SfM); photogrammetry; mineral mapping; minimum wavelength mapping; Maarmorilik; Riotinto

\section{Introduction}

Hyperspectral imaging has been increasingly used to support mineral exploration and geological mapping campaigns. The obtained spectral signatures provide detailed information about the composition of rocks and the occurrence of economic minerals. The hyperspectral instruments are conventionally operated with a nadir viewing angle, comprising different scales of area coverage and spatial resolution by operation on satellite [1,2], airplane [3-6] or drone [7]. Depending on the acquisition altitude, a varying influence of the atmosphere between sensor and target, as well as illumination differences due to topography, can be observed in the acquired spectral 
imagery. Numerous approaches have been introduced in an attempt to overcome these effects: Atmospheric influences are either corrected by atmospheric modelling using radiative transfer models (e.g., [8-10]), the use of ground targets with known or assumed spectra (empirical line calibration [11], flat field correction [12], dark object subtraction [13]), or a combination of both [14]. Whereas radiative transfer models rely on the correct input of a set of external parameters and are mainly used for satellite and airborne data, the use of ground targets, dark objects, or flat fields provides a much more straightforward approach. However, these methods require a spatial resolution high enough to resolve spectrally uniform reference target(s) and/or a reasonable knowledge on the spectra of those materials present, and are therefore mainly used for drone- or airborne data with low acquisition altitudes (e.g., $[7,15])$.

In the last few years, a ground-based approach of using hyperspectral sensors for geological applications has emerged. A tripod-mounted device can be used to rapidly acquire spectrally and spatially highly resolved data of near-vertical geological outcrops, i.e., spatial orientations that are not (or hardly) observable by nadir-faced instruments. Near-vertical outcrops may comprise steep mountain slopes, water-faced cliffs, open pit mine walls, and road cuts. Particularly in arctic or humid regions, where snow and ice, lichens, or dense vegetation cover the Earth's surface, the investigation of such natural or artificial cuts through the strata might be the only possibility to obtain spectral information of the local geology. Currently, ground-based hyperspectral sensors for geological applications are nearly exclusively used for targets at distances between one to several hundred metres (e.g., [16-18]). Within this range, the spatial resolution varies between centimetre and decimetre scale, enough to resolve even small-scale mineral compounds and fault systems. Another significant benefit of close-distance measurements is the negligible influence of the atmosphere, which potentially voids the need for an elaborate radiometric correction. Instead, an empirical line approach using reference targets with the same orientation, distance, and illumination conditions as the geological target is sufficient for the conversion to reflectance. However, observing a geological target at close range is not always feasible or reasonable. In particular, larger and vertically oriented targets such as steep mountain slopes, sea- or lake-faced cliffs, and walls of large open pit mines are often only fully visible from an opposing location such as a neighbouring mountain [19], pit level, shore, or even a boat [20]. The distance between the sensor and the target of interest can then easily exceed the close-range and extend to several kilometres. These distances not only lead to major atmospheric distortions, but also prevent the logistical setup of visible reference targets for radiometric correction as well as ground control points for image georeferencing. Additionally, owing to the much larger scale of the observed surface and the ground-based viewing perspective, pixels within one scene can represent a range of different distances and orientations, leading to highly variable radiometric distortions. For those reasons, correction methods established for nadir acquisitions are not applicable or need to be intensely modified to account for the special conditions of long-range ground-based sensing.

In this paper, we meet these additional challenges and present a novel workflow that allows the creation of fully corrected long-range ground-based hyperspectral image data for geological applications. In addition to sensor-induced geometric distortion corrections, the workflow now includes a new approach for the radiometric correction of long-range ground-based data as well as a topographic correction algorithm based on integration with 3D surface data using automatic matching algorithms. We also describe a detailed methodology for producing 3D hyperclouds, i.e., geometrically correct representations of the hyperspectral datacube, for the display of generated spectral mapping products. The methods presented will be included in the open source Mineral Exploration Python Hyperspectral Toolbox MEPHySTo [7]. We demonstrate the methodology in two areas that differ in geology, climate, and scientific objectives. The first area is located in an arctic environment, where two hyperspectral scans acquired from different points of view are used to detect and map mineralogical variations in the composition of the Mârmorilik Formation marbles in West Greenland. The single result map is integrated with photogrammetry data to provide spatial context and a $3 \mathrm{D}$ view that can be integrated into 3D modelling. The second dataset was acquired at the now-abandoned open pit 
mine Corta Atalaya near Minas de Riotinto, Spain. The Spanish dataset demonstrates the applicability of the corrected dataset for alteration zone mapping of a massive sulphide deposit under hot and dusty conditions as well as the integratability of datasets acquired at different times.

\section{Areas of Investigation}

\subsection{Nunngarut Peninsula, Maarmorilik, Greenland}

The first study area is located in central West Greenland, within the regions of Uummannaq Fjord and Karrat Isfjord (Figure 1). The investigated area covers large parts of the Nunngarut Peninsula at the Qaamarujuk fjord, where the former mining town of Maarmorilik is located. The nearby Black Angle $\mathrm{Pb}-\mathrm{Zn}$ deposit is separated from the Nunngarut Peninsula by the smaller Affarlikassaa fjord. The study area belongs to the Mârmorilik Formation, a $1600 \mathrm{~m}$ thick carbonate-dominated rock sequence representing the southernmost stratigraphy of the Paleoproterozoic Karrat Group [21]. It was deposited between 2.1 and $1.9 \mathrm{Ga}$ in an epicontinental marginal basin as platform carbonates [21], nonconformably overlies a suite of strong deformed Archean orthogneisses, and is overlain by flysch-type metasedimentary rocks of the Nûkavsak Formation [22].

The Mârmorilik Formation is dominated by dolomite-rich marbles in the lower part and calcite-rich marbles in the upper part. Locally, interbedded horizons of quartzites, tremolite-rich marbles and possible metamorphosed evaporites in the form of anhydrite occur [21,23]. The Black Angel Mississippi-Valley-Type (MVT) Pb-Zn deposit is emplaced within the Mârmorilik Formation [22,24], causing an overprint of the marbles by basal brines. The whole succession of Archean basement and the Karrat Group was strongly folded and thrusted by the Nagssugtoqidian-Rinkian orogenesis. During this orogenesis, the Mârmorilik Formation underwent at least three phases of deformation [19], leading to recrystallisation and metamorphism under high greenschist to amphibolite facies conditions [25]. The Mârmorilik Formation is interpreted to be the lateral equivalent to the Qaarsukassak Formation [26], and together they form a several hundred square kilometre large prospective region for zinc mineralisation $[19,27]$.

\subsection{Corta Atalaya, Riotinto, Spain}

Corta Atalaya, near Minas de Riotinto in the province of Huelva (southern Spain), is, with a size of $1200 \times 900 \mathrm{~m}$ and a maximal depth of $365 \mathrm{~m}$, one of the most famous open pits of the Riotinto mining district (Figure 1). The Volcanogenic Massive Sulphide (VMS) mineralisation of Riotinto is associated with the Iberian Pyrite Belt (IPB), which is considered to host the largest concentration of massive sulphides in the Earth's crust [28]. The IPB is located in a north-vergent fold and thrust belt of late Variscan age [29] extending from east of Setubal, Portugal, to north of Seville, Spain, and has been extensively mined for copper, manganese, iron, and gold since the Bronze Age. At Riotinto, the lithostratigraphic succession can be divided into three units (from bottom to top): (i) phyllites and quartzites; (ii) slates, basalt sills, felsic volcanics (rhyolites and dacites); and (iii) the so-called Culm series (greywackes and slates). The stratabound, VMS lenses are located within felsic volcanics of Upper Devonian to Lower Carboniferous ages [28]. Zones of chloritic and argillitic alteration are associated with the massive sulphide mineralisation. Stockwork zones occur underneath the lenses in the vicinity of faults [28]. A gossan usually forms in the cap-rock above. The deposit of Riotinto itself is situated in the hinge of an E-W-trending anticline with an east-plunging fold axis. Corta Atalaya is located on the southern flank of this so-called Riotinto anticline. Stockwork and massive ore bodies are associated with E-W-striking thrusts. A set of later NW-SE-oriented transverse faults offsets the Riotinto anticline. The most prominent of these faults, the Falla Eduardo, displaces the massive sulphide body San Dionisio about $150 \mathrm{~m}$ to the south and finds its continuation in the Filón Sur ore body east of Corta Atalaya [28]. The massive sulphide body San Dionisio, which was exploited in Corta Atalaya, originally had reserves of 100 million tonnes. Originally, the mine was dedicated to the extraction of iron and copper sulphides (mainly pyrite with smaller amounts of chalcopyrite). 
The initial objective was to extract copper from copper sulphides, but, subsequently, the sulphur contained in pyrite was used for the manufacturing of sulphuric acid until final closure of the open pit in 1991 [28].
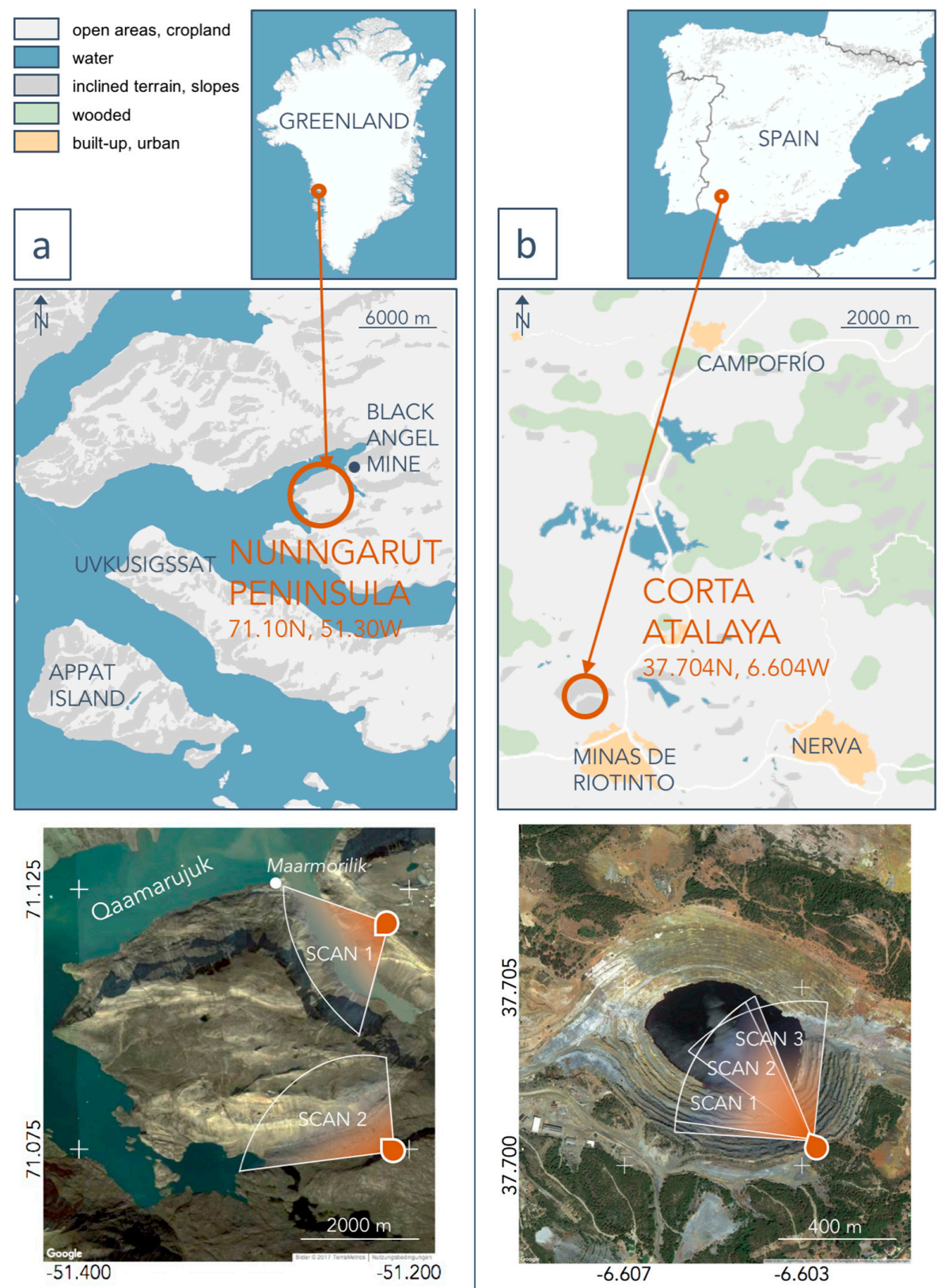

Figure 1. Location of the two investigated sites and schematic coverage of the acquired AisaFENIX hyperspectral imagery at: (a) Nunngarut Peninsula, Maarmorilik, Greenland; and (b) Corta Atalaya open pit, Minas de Rio Tinto, Spain.

\section{Data Acquisition}

\subsection{Hyperspectral Imagery}

The hyperspectral image (HSI) data was acquired using a SPECIM AisaFENIX push-broom scanner. The scanner has 384 swath pixels with 624 spectral bands each, covering the visible and near-infrared (VNIR) to short-wave infrared (SWIR) range between 380 and $2500 \mathrm{~nm}$. The spectral resolution (Full Width at Half Maximum-FWHM) varies between $3.5 \mathrm{~nm}$ for the VNIR and $12 \mathrm{~nm}$ 
in the SWIR at a spectral sampling distance of about $1.5 \mathrm{~nm}$ (VNIR) and $5 \mathrm{~nm}$ (SWIR), respectively. By mounting the instrument on a rotary stage, a continuous hyperspectral image with a vertical field of view (FOV) of $32.3^{\circ}$ and a maximum scanning angle of $130^{\circ}$ could be acquired in one measurement. During the measurements, the GPS position of the camera, acquisition time, and general viewing direction (from here on referred to as 'camera angle') of the scan were recorded. A Spectralon SRS-99 white panel was set up near the camera within the FOV and with a similar general orientation as the imaged outcrop.

\subsection{Photogrammetry Data/3D Data}

Images for reconstruction of surface geometry were recorded using precalibrated RGB and hyperspectral cameras. In the case of Maarmorilik, a Nikon D800E with a $35 \mathrm{~mm} 1.4$ Zeiss lens was used from a helicopter. The 3D pointcloud of Corta Atalaya was based on fusion of drone-borne images from a Rikola Hyperspectral Imager (red band) and a Canon EOS M with EF-M 22 mm f/2 STM lens (as grey-scale image). Camera positions were obtained from an attached GPS device, whereas the imaging geometry was reconstructed using a Structure from Motion (SfM) and MultiView Stereo (MVS) workflow. Prior to the photogrammetry workflow, image distortions were removed.

\subsection{Validation Sampling}

Samples of the main lithologies were taken for a validation of the correction workflow and of the mineral mapping results. Sample locations were recorded using a handheld GPS device. Spectra of representative fresh and altered rock surfaces were acquired in situ using a portable Spectral Evolution PSR-3500 spectro-radiometer using a contact probe ( $8 \mathrm{~mm}$ spot size) with an internal, artificial light source. Its spectral resolution is $3.5 \mathrm{~nm}(1.5 \mathrm{~nm}$ sampling interval) in VNIR and $7 \mathrm{~nm}(2.5 \mathrm{~nm}$ sampling interval) in the SWIR, resulting in 1024 channels in the spectral range from 350 to $2500 \mathrm{~nm}$. Radiance values were converted to reflectance using a calibrated PTFE panel with $>99 \%$ reflectance in VNIR and $>95 \%$ in SWIR (either Spectralon SRS-99 or Zenith Polymer). Each spectral record consisted of 10 individual measurements, which were taken consecutively and then averaged.

\section{Processing Workflow}

\subsection{Preprocessing of Hyperspectral Raw Data}

The acquired raw hyperspectral datasets are first converted to At-Sensor-Radiance using dark-current subtraction followed by image normalisation and multiplication of sensor- and band-specific radiometric calibration data (Figure 2). In a second step, two geometric corrections of sensor-specific optical distortions need to be applied. The first effect is a distortion along the FOV comparable to the distortion of fish-eye lenses. This leads to an increasing shortening of the image from the centre to the upper and lower image boundaries. The second effect can be described as slit bending and refers to a curved recording of the currently scanned (straight) line. Both effects can be removed by applying correction values for each pixel in the FOV. The required parameters are included in a lookup table provided by the manufacturer of the sensor. In the case that several scans of the same scene have been acquired with the same settings, a stacking and averaging of those scenes can be performed at this point. By image stacking, the signal-to-noise ratio can be increased, reducing possible temporal illumination variations due to changing cloud cover. 


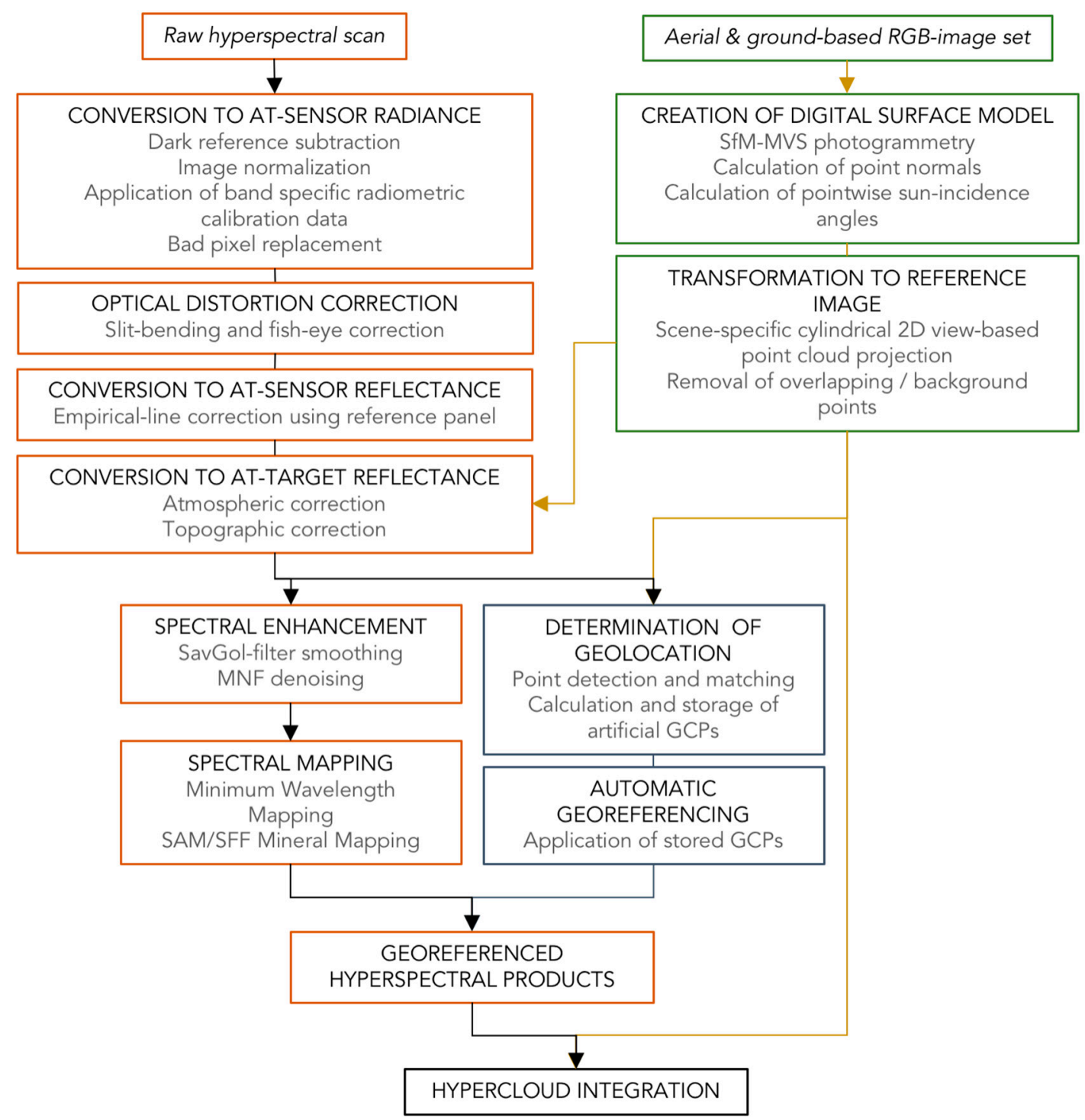

Figure 2. Schematic workflow for the correction, processing, and $3 \mathrm{D}$ integration of long-range ground-based hyperspectral imagery.

\subsection{Radiometric Correction of Hyperspectral Radiance Data}

Subsequent to the transformation of the raw hyperspectral data into radiance, a conversion to at-sensor reflectance needs to be applied, which can be achieved using a white reference panel placed near the sensor. This Spectralon (SRS-99) reference target is close to an ideal Lambertian reflector with $>99 \%$ reflectance in the VNIR and $>95 \%$ in the SWIR. Its exact reflectance spectrum is known and can be used for an empirical line correction of the radiance data. Hereby, a linear regression between the image radiance values and the reference reflectance values is calculated and applied for each band.

Depending on the imaging distance and the climatic conditions, the resulting at-sensor reflectance image may still feature atmospheric distortions (see Figure 3). In contrast to air- or spaceborne data, the scene-specific intermediate atmospheric layer can be assumed to have a uniform composition with only negligible variations. Nevertheless, the amount of atmospheric influence varies for each pixel and depends mainly on the distance between sensor and target, but can be also influenced by local variations, e.g., differing intensities of upwelling water vapour. 

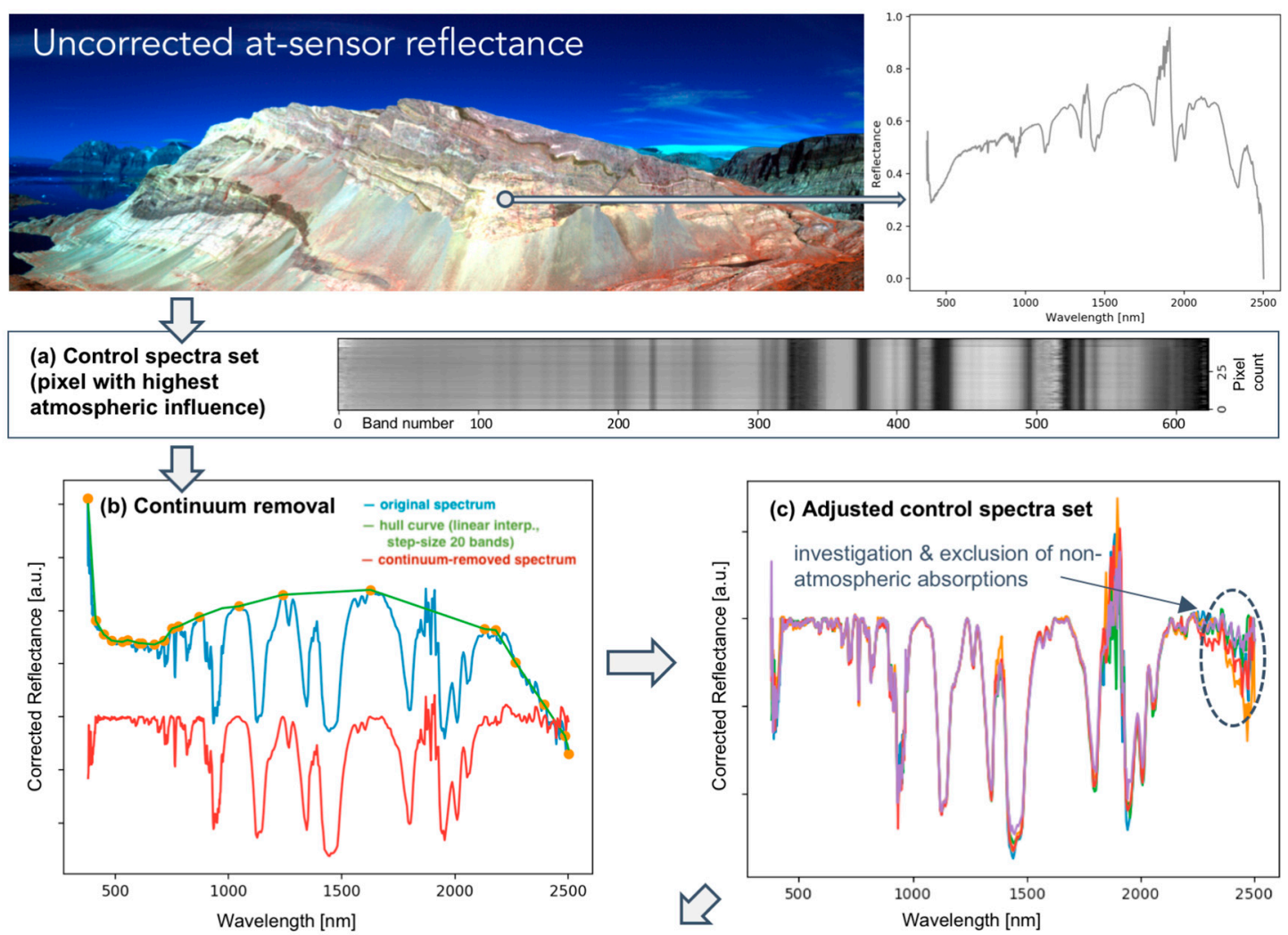

(d) Final control spectrum and selection of the control feature

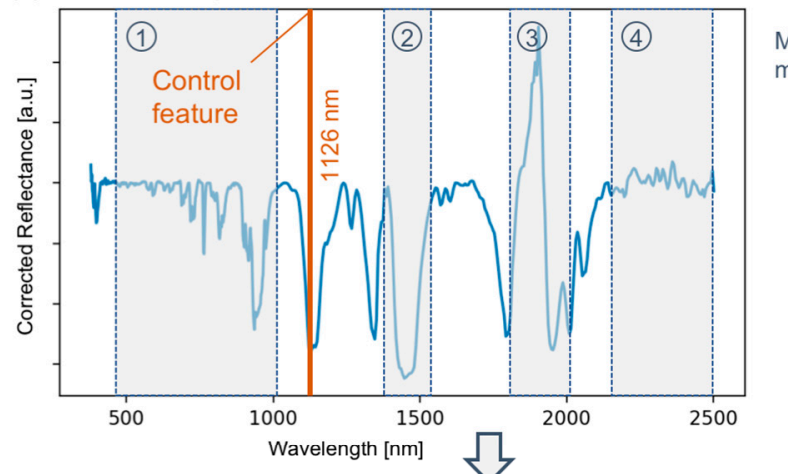

Most important wavelength ranges for mineralogy-related features
(1) $\mathrm{Fe}^{2+}$
$\mathrm{Fe}^{3+}$
$\mathrm{Nd}^{3+}$
(2) $\mathrm{OH}$
(3) $\mathrm{H}_{2} \mathrm{O}$
(4) $\mathrm{Al}-\mathrm{OH}$
$\mathrm{CO}_{3}$
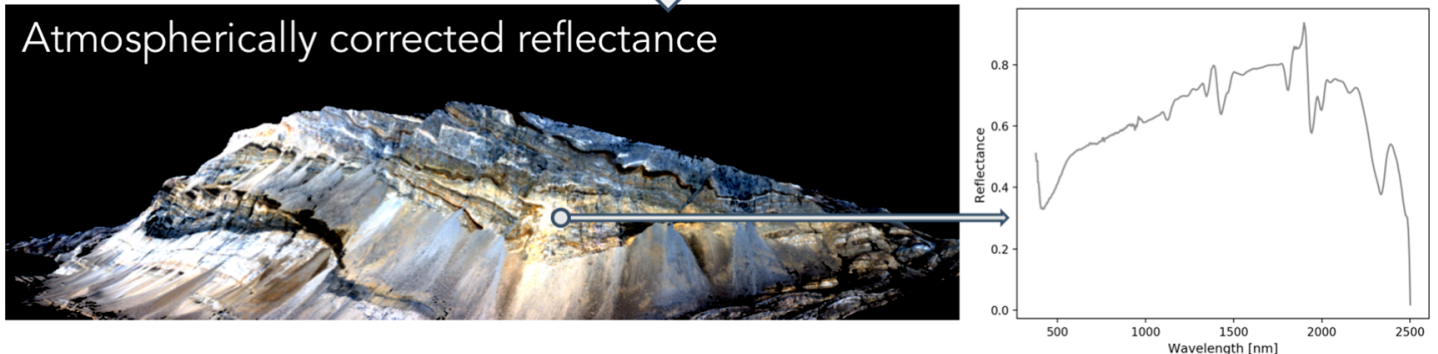

Figure 3. Atmospheric correction workflow on the example of the Maarmorilik marble cliffs (Nunngarut, Scan 2). Hyperspectral images are displayed using spectral true colour representative bands (R: $640 \mathrm{~nm}$ G: $550 \mathrm{~nm}$ B: $470 \mathrm{~nm}$ ). See text for a detailed description. (a) Control spectra set; (b) continuum removal; (c) adjusted control spectra set; (d) final control spectrum and selection of the control feature.

Given these circumstances, we attempt to perform a radiometric correction to remove atmospheric distortions using a single atmospheric correction spectrum for each scene. The intensity of correction needs to be varied according to the amount of atmospheric distortion. For the correction approach 
to be robust and independent from additional parameters or knowledge about the composition of the influencing atmospheric layer, the atmospheric correction spectrum is derived directly and automatically from the hyperspectral image itself. Hereby, the correction spectrum is a comprehensive representation of all scene-abundant spectrally influencing atmospheric components, which may encompass atmospheric dust, water vapour, and other atmospheric gases. The correction spectrum is neither selective nor restricted to defined components and is thus applicable for any atmospheric setting.

Owing to the assumed constant composition of the atmosphere over the scene, the depths of all atmosphere-related features should change equally if the atmospheric influence is altered. This approach allows us to evaluate the amount of atmospheric influence for each pixel by the depth of only one atmospheric absorption feature and eliminates the need for atmospheric models, additional calibration targets, and distance measurements. The now-called control feature must necessarily be both common in all possibly occurring atmospheric compositions and strong enough to be detectable even for low atmospheric influence. Additionally, it should not overlap with any characteristic mineralogy-related features to avoid interference and miscorrections. The absorption band we found to fulfill these conditions best is situated at $1126 \mathrm{~nm}$ (Figure 3d) and is related to atmospheric water vapour [14].

The atmospheric correction workflow consists of several steps, which can also be retraced in Figure 3:

1. Masking of sky-related pixels: All image pixels representing sky and sky reflected by mirroring surfaces such as water are masked out automatically from the reflectance image using a ratio between the image bands located at 410 and $890 \mathrm{~nm}$. These wavelength positions are set to encompass two ends of the extreme decline in VNIR reflectance that is specific for sky-related spectra. This characteristic shape leads to a usually very distinct ratio difference between sky and non-sky pixels. In our examples, the masking threshold was most successful in a ratio range between 1.0 and 2.0.

2. Determination and processing of possible correction spectra: The depth of the control feature at $1126 \mathrm{~nm}$ is calculated for all remaining pixels. All pixel spectra with a control feature depth within $80-100 \%$ of the maximum are extracted as a control spectrum set (Figure 3a), which will be used to determine the final atmospheric correction spectrum. A continuum removal and an equalisation of the control feature depth are applied on each spectrum of the control set separately. The respective continuum hull is calculated using a linear interpolation of stepwise acquired maxima all over the respective spectrum (Figure 3b). The moving window for the continuum hull calculation can either be set to a fixed step size or restricted to specific stored wavelength ranges that are located outside or at the edge of known atmospheric absorption windows.

3. Exclusion of nonatmospheric features: Some spectra of the resulting equalised control spectra set may still contain additional nonatmospheric absorptions. These features should be excluded from the correction spectrum to avoid a weakening or deletion of important mineralogical features during the atmospheric correction process. In contrast to atmospheric features, nonatmospheric absorptions occur with differing intensities and only in a spectral subset of the control spectra (Figure 3c,d). They can be excluded from the control spectrum set by maintaining only the highest of all spectral values for each wavelength. The used threshold can be varied manually if needed.

4. Calculation and application of the final control spectrum: The remaining spectral information is averaged for each wavelength to reduce possible noise. The outcome of the whole procedure provides a single continuum-removed correction spectrum containing solely the characteristic atmospheric contribution of the analysed hyperspectral image (Figure 3d). The atmospheric correction itself is performed pixelwise. For each pixel, the intensity of the correction spectrum needs to be adjusted to both depth and reflectance value of the control feature in the pixel spectrum. The correction itself is then achieved by a simple division of the pixel spectrum by the 
adjusted correction spectrum. The original reflectance intensities are maintained in the corrected image spectra during that process.

The processing time for the automatic correction of a hyperspectral scan with the spatial and spectral dimensions as in our examples is less than one minute. Thus, the method is extremely timeand effort-saving and can be easily integrated into a batch-processing workflow.

Depending on the Signal-to-Noise ratio (SNR) of the processed dataset, a subsequent Minimum Noise Fraction (MNF) smoothing can be advantageous. MNF smoothing entails a transformation of the image into MNF space, a rejection of bands with low SNR, and a subsequent back-transformation into the original image space [30]. The number of MNF bands to be rejected can be determined by looking at the eigenvalue function of the calculated MNF bands, which reaches a plateau after a sharp increase and suggests a rejection if the asymptotic eigenvalue function approaches a linear function [31].

\subsection{SfM-MVS Photogrammetry}

The Digital Surface Model is derived from aerial and ground-based images using the Structure-from-Motion MultiView Stereo (SfM-MVS) algorithms in Agisoft Photoscan Professional 1.2.5. SfM-MVS is a low-cost, user-friendly workflow combining photogrammetric techniques, 3D computer vision, and conventional surveying techniques. It solves the equations for camera pose and scene geometry automatically using a highly redundant bundle adjustment [32,33]. A typical SfM-MVS workflow towards a final surface model consists of the following eight steps [33,34]:

1. Detection of characteristic image points;

2. Automatic point matching using a homologous transformation;

3. Keypoint filtering — this step is crucial for model accuracy and validation of later results [35];

4. Iterative bundle adjustment to reconstruct the image acquisition geometry and internal camera parameters;

5. Scaling and georeferencing of the intrinsic coordinate system to available reference points (GCPs) or camera coordinates and optimisation of the resulting sparse cloud;

6. Applying MultiView Stereo algorithms (dense matching) to compute the dense cloud-the resulting dense cloud is the basis for the geometric correction of the hyperspectral data;

7. Interpolation of the dense cloud by, e.g., Meshing or Inverse Distance Weighting (IDW), to retrieve a Digital Surface Model (DSM);

8. Texturising of the 3D model.

\subsection{Calculation of Sun Incidence Angles for Topographic Correction}

Knowledge of the sun incidence angle for each pixel of the hyperspectral image is crucial for its topographic correction. In contrast to nadir data, vertical outcrop scans can have multiple pixels located at any given latitude/longitude coordinate position, which can be only spatially differentiated by their elevation values. Therefore, common tools for the calculation of slope, aspect, and sun incidence angle of Digital Elevation Models (DEM) cannot be applied here. Instead, we calculate the sun incidence angle for each individual point of the point cloud generated in Section 4.3 as the angle between the point normal and the sun vector (Figure 4a). The point normals were either calculated during the point cloud construction or can be computed retroactively using a triangulation of neighboring points. The sun vector is characterised by

$$
\text { sunvec }=\left(\begin{array}{c}
\cos (S E) * \sin (A Z) \\
\cos (S E) * \cos (A Z) \\
\sin (A Z)
\end{array}\right)
$$


with $S E$ being the sun elevation angle and $A Z$ the sun azimuth at the given date, time, and position of the acquisition. The calculated sun incidence angles are stored as additional point properties in the point cloud file and retained in all following processing steps.

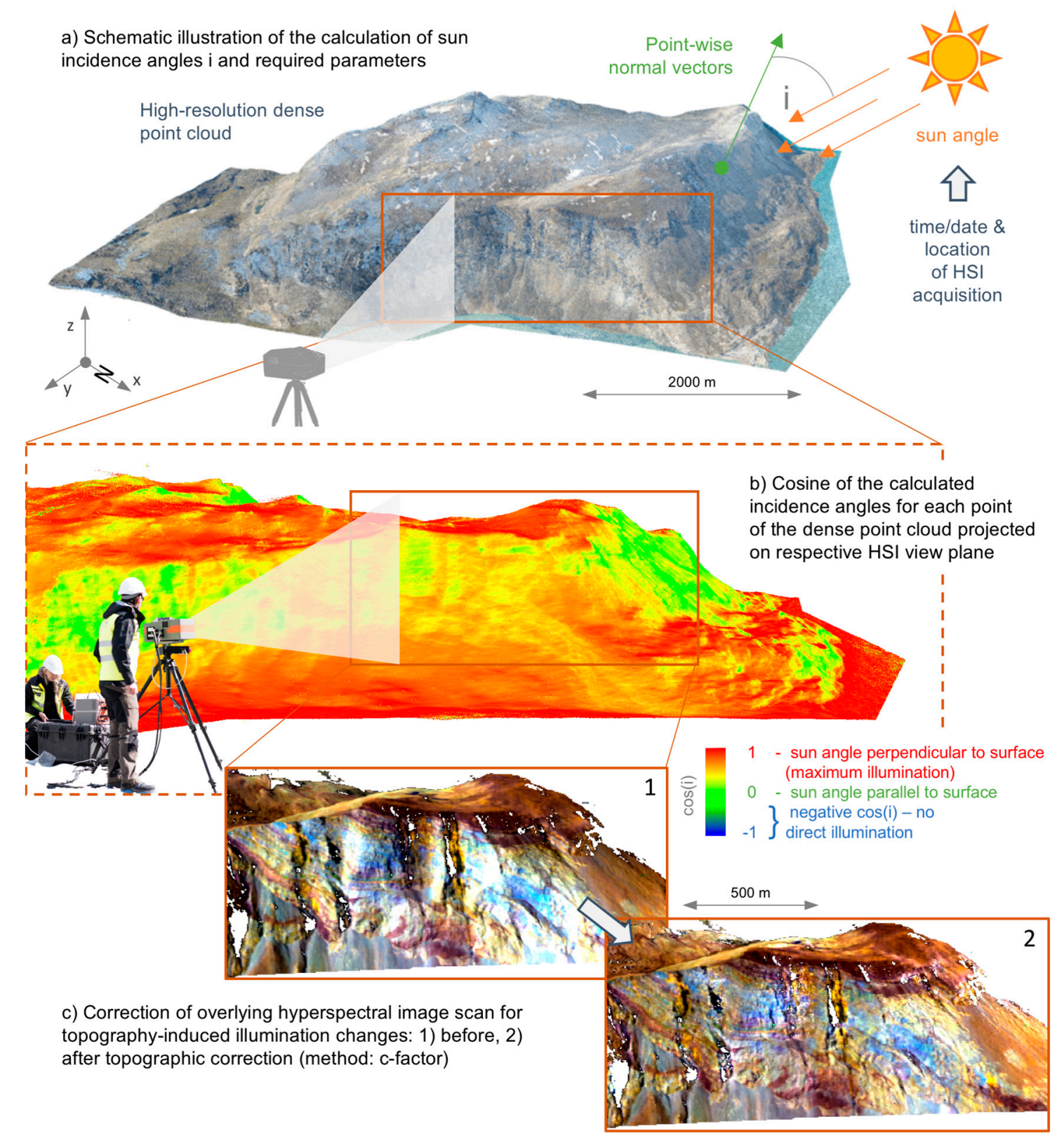

Figure 4. Topographic correction of vertical hyperspectral image (HSI) (Nunngarut, Scan 1). (a) Schematic illustration of the calculation of sun incidence angles i and required parameters; (b) cosine of the calculated incidence angles for each point of the dense point cloud projected on respective HSI view plane; (c) correction of overlying hyperspectral image scan for topography-induced illumination changes: (1) before, (2) after topographic correction (method: c-factor).

\subsection{Projection of Pointcloud and HSI Matching}

An integration of 2D hyperspectral data and 3D point cloud data is needed for topographic correction and final creation of the 3D hypercloud. In order to facilitate automatic matching and reduce distortion in the subsequent wrapping process, the point cloud is projected onto a 2D surface in a way that resembles the view of the hyperspectral camera during image acquisition. It is crucial here that 
through the entire process of ensuing transformations the original coordinates of each point of the cloud are stored as additional parameters. Due to the push-broom character of the sensor, a simple orthographic projection of the point cloud onto a plane is not suitable. Instead, the point cloud is first transformed so that the camera position is set as the new origin and the camera viewing angle is set along the $y$-axis of the coordinate system by

$$
\text { Transformed points }=\text { Original points }- \text { Camera Position } *(- \text { Camera Angle }) \text {. }
$$

The spatial relation between point cloud, camera angle, and camera position in the transformed coordinate system is displayed in Figure 5.

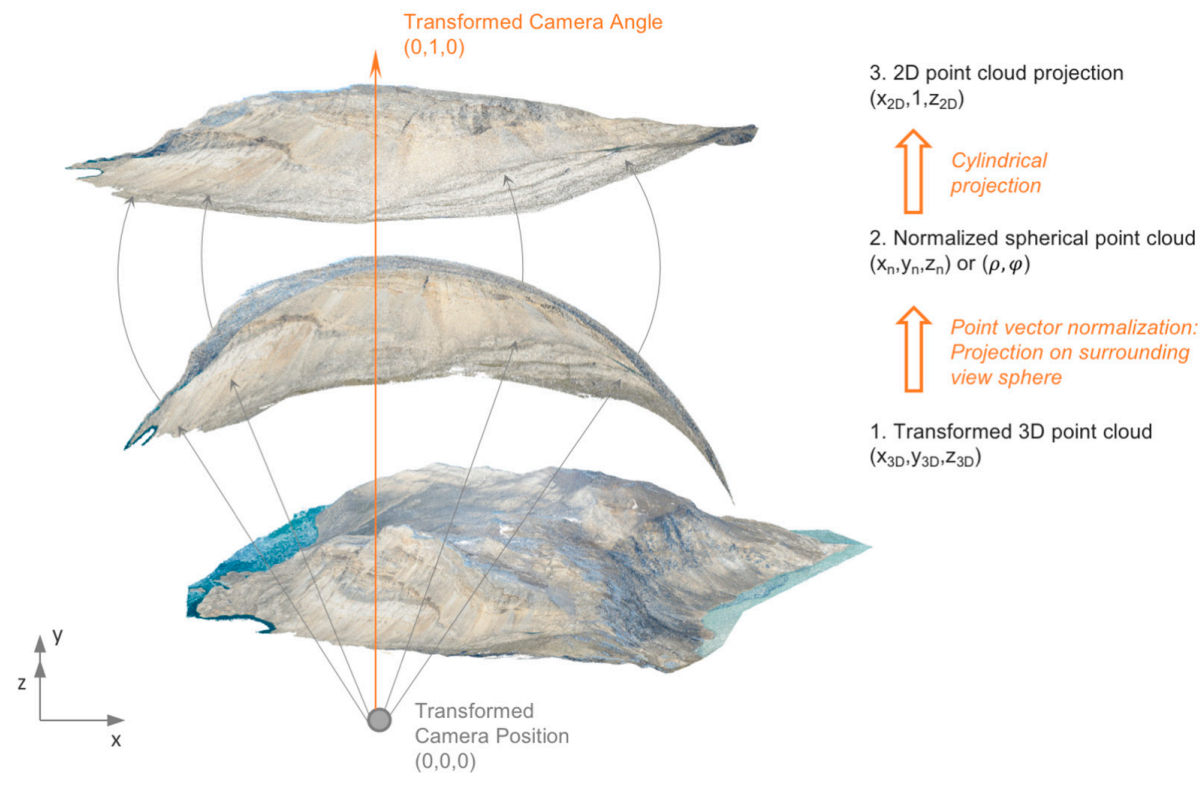

Figure 5. Schematic workflow of the point cloud transformation and projection to create a 2D image resembling the panoramic view of a push-broom hyperspectral imager (Nunngarut, Scan 2).

Each point coordinate of the transformed point cloud now corresponds to the vector $\vec{v}$ between the transformed camera position at $(0,0,0)$ and the point at $\left(x_{3 D}, y_{3 D}, z_{3 D}\right)$. If we assume that the camera FOV is a subset of a virtual surrounding view sphere with the center at the camera position, the point cloud can be projected onto that sphere by normalizing each point vector by

$$
\begin{gathered}
\left(x_{n}, y_{n}, z_{n}\right)=\frac{\vec{v}}{|\vec{v}|} \\
\text { with } \vec{v}=\left(\begin{array}{l}
x_{3 D} \\
y_{3 D} \\
z_{3 D}
\end{array}\right) ;
\end{gathered}
$$

see also Figure $5 b$.

The projected point cloud is now unfolded onto a 2D plane using a cylindrical projection with

$$
\begin{gathered}
x_{2 D}=\rho \text { with } \rho=\tan ^{-1}\left(y_{n} / x_{n}\right), \\
y_{2 D}=1, \\
z_{2 D}=\tan \varphi \text { with } \varphi=\pi / 2-\tan ^{-1}\left(\sqrt{x_{n}^{2}+y_{n}^{2}} / z_{n}\right),
\end{gathered}
$$

with $x_{2 D}$ and $y_{2 D}$ being the Cartesian coordinates of the created 2D image, and with $x_{n}, y_{n}$, and $z_{n}$ or $\rho$ and $\varphi$ being the Cartesian or spherical coordinates of the normalised 3D point cloud, 
respectively (Figure 5c). The angle at which the cylinder is cut for the projection can be set by an additional parameter.

The projection into 2D space considers all of the points in the true line of sight of the hyperspectral camera, which includes points hidden behind points in the foreground (front points), such as the backside of a mountain (back points). This leads to artefacts within the created 2D image (see Figure 6a) and would adversely affect subsequent processing steps. Using a maximum threshold for the original spatial distance between neighbouring points, the adverse back points can be removed. To ensure a fast processing even for huge point clouds, a moving window is used to process several points at once. For each applied window, the contained point with the closest distance to the camera position is found. This distance can be calculated from the original coordination of the point cloud, which is still saved as additional point parameters. Hereby, it is advantageous to use only the original coordination axis that was closest to the original camera angle. While neighbouring front points show a similar location with generally from decimetres to a few metres difference (depending on the spatial accuracy of the data), back points mostly feature locations far off, with distances of several tens to hundreds of metres from the camera-closest front point. According to this, the threshold is set and all resulting back points are deleted (Figure $6 b$ ). Due to the nature of this workflow, a smaller window size guarantees a higher accuracy, but also a higher computation time.

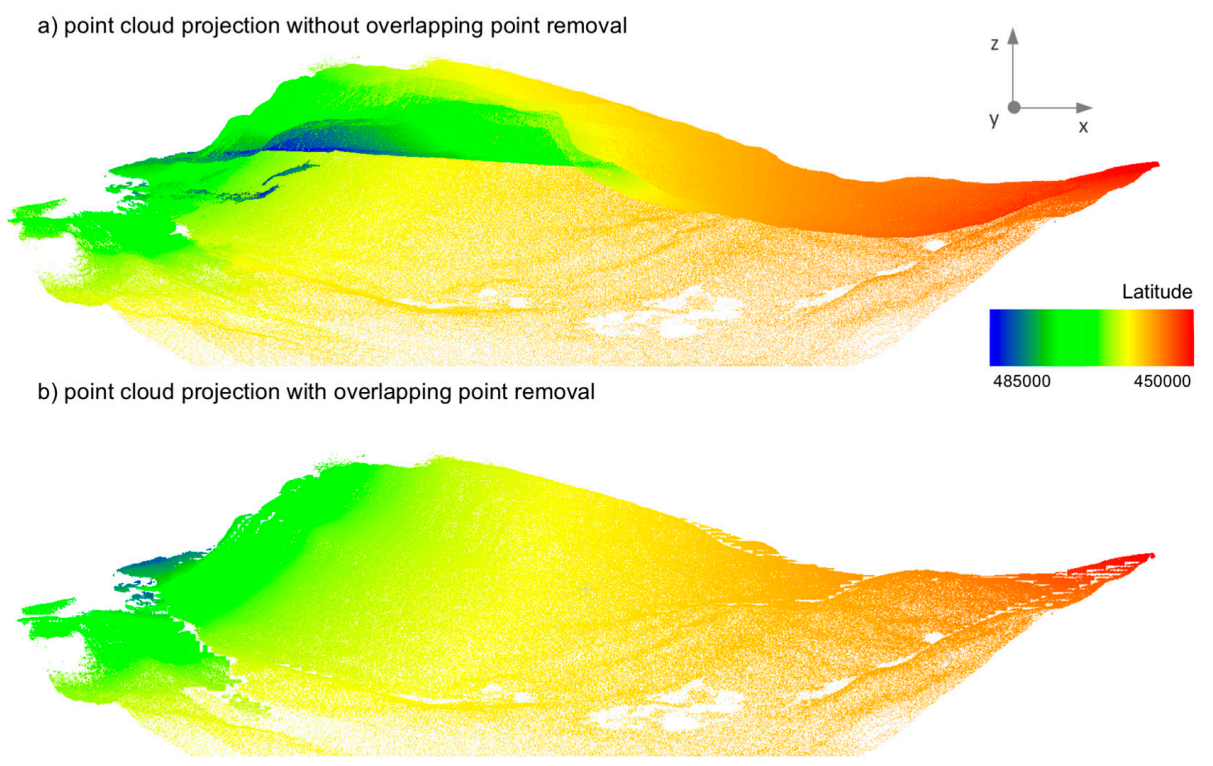

Figure 6. Effect of the overlapping point removal on the quality of the 2D point cloud projection image on the example of Nunngarut, Scan 2. The original $x$-coordination of the points is illustrated by a colour gradient. (a) Point cloud projection without overlapping point removal; (b) point cloud projection with overlapping point removal.

After the deletion of the interfering back points, the remaining front points are interpolated into a raster with a spatial resolution similar to or slightly higher than the spatial resolution of the hyperspectral data. Apart from RGB colour information, this ortho-image has four additional bands containing the original point cloud coordinates and the calculated sun incidence angles. The created RGB raster can now be used for an automatic co-registration of the hyperspectral image. The matching workflow used for the co-registration will be part of the MEPHySTo toolbox presented in Jakob et al. [7] and is also successfully adapted and used for the integration of vessel-based hyperspectral data and $3 \mathrm{D}$ point clouds in an accompanying paper [20]. The workflow is based on the SIFT (Scale-invariant feature transform) algorithm [36], which, from both images, extracts local features or keypoints that are invariant to translation, rotation, and scale and partly invariant to affine or 3D projection and illumination changes. Using the FLANN (Fast Library for Approximate Nearest Neighbors) matching 
algorithm library [37], correlating point pairs between both keypoint sets are found. The best-matching point pairs are used as control points for a polynomial warping of the hyperspectral image to fit on the RGB raster. After the co-registration, each overlapping point of both datasets features high-resolution spectral data, geographic position, and elevation, as well as the sun incidence angle at the time of the acquisition.

\subsection{Topographic Correction of Referenced HSI}

The topographic correction is similar to the approach described in Jakob et al. [7]. The main difference is the calculation of pixel-specific sun incidence angles, which is described above in Section 4.4. The calculated angles can now be used to apply a topographic correction algorithm. The c-factor method returned the best correction results of all the methods implemented in the toolbox and achieved a very smooth and accurate correction even for high illumination differences (see Figure 4c). The topographically corrected image is calculated by

$$
r e f_{c}=r e f_{o} * \frac{\cos (z)+c}{I L+c}
$$

where $c$ is $a / m$ from the linear regression of $r e f_{o}=a+m * I L$ and $I L=\cos (i)$ [38]. The $c$-factor approach is applied separately for each spectral band. The correction of a common hyperspectral scan usually takes less than a minute. For very dark and deeply shaded regions of the image, pixels can be heavily overcorrected. These pixels are characterised by extreme, up to infinite values, which exceed the common value range of reflectance data distinctly. The affected pixels are detected and masked using appropriate thresholds, which are set according to the spectral reflectance minimum and maximum of the topographically uncorrected image (e.g., 0 and 1).

\subsection{Minimum Wavelength Mapping}

The finally corrected HSI can now be used for subsequent mapping and interpretation. In the present paper, a Minimum Wavelength (MWL) mapping approach is exemplarily used to test the quality and applicability of the data for mineral mapping.

MWL mapping using the Wavelength Mapper $[39,40]$ aims to estimate the position of the deepest absorption feature in a given wavelength range. The position of the absorption minimum is a key to link surface mineralogy to subtle variations in mineral composition (e.g., shift of the Al-OH feature depending on the coordination of the Al). First, a hull curve is calculated and divided from the spectra. Second, position and depth of the most prominent absorption are computed using a second-order polynomial function. These two parameters can be used to create MWL position maps, where the position of the investigated feature is displayed by a colour change, while the colour intensity is controlled by the absorption depth.

The success of the MWL mapping approach depends crucially on the analysis of subtle changes of position and depth of mostly small mineralogical absorption features. Therefore, it is an excellent possibility to evaluate image correction methods, which affect both the intensity ratio between single pixels of the image (topographic correction) and the shape of the spectrum itself (radiometric and atmospheric correction). In this context, the successful removal of distortions is as important as maintaining existing and real intensity relations and spectral features.

\subsection{Generation of Hyperclouds}

At the end of the workflow described above, each pixel of the HSI (and any HSI mapping product) has an assigned geographic position and elevation through the corresponding pixel in the projected and rasterised 2D point cloud. By deriving this information for each pixel of the spectral raster, we can create a so-called "hypercloud", which visualises the spectral data as a 3D point cloud. The displayed data can comprise any spectral data or result, such as simple reflectance data, results from decorrelation, and endmember mapping methods, or MWL mapping results as presented 
here. The hypercloud can be displayed and processed further with respective 3D software such as CloudCompare (open-source GPL software, retrievable from http:/ / www.cloudcompare.org/) or SKUA-GOCAD (Emerson/Paradigm, Houston, United States). If the hyperspectral survey consisted of several scans covering different parts of the observed area, the creation of hyperclouds can be an excellent option to set the single mapping results into a spatial context by simultaneously displaying or merging multiple hyperclouds. The 3D hypercloud also allows for integration with other spatial datasets such as boreholes or structural observations.

\section{Results}

\subsection{Nunngarut Peninsula, Maarmorillik, Greenland}

Two hyperspectral scans were acquired from two different scanning locations, covering the largest part of the south and east coast of the Nunngarut Peninsula (Figure 1a). The approximate distance between sensor and observed target ranged between 2 and $5 \mathrm{~km}$ for the majority of all outcrop-related image pixels. Despite overall dry and sunny conditions during acquisition, numerous sharp atmospheric absorption features within the spectral data (see Figures 3 and 7) suggested a high influence of the atmospheric layer between the sensor and the target. Figure 7 displays the known major atmospheric contributions (in this case water vapour, $\mathrm{CO}_{2}, \mathrm{O}_{2}$, and $\mathrm{O}_{3}$ ) to the overall observed atmospheric perturbances and the resulting calculated spectrum used for the corrections. We showcase that the radiometric correction approach presented here allows us to remove the influence of the atmosphere almost completely, whereas typical mineral-related spectral features of the Mârmorilik Formation remain. In the resulting atmospherically corrected target spectrum, the remaining absorption features are indubitably attributable to characteristic mineral features. Besides the distinct carbonate feature of the Mârmorilik marbles, the characteristic $\mathrm{AlOH}$ and $\mathrm{OH} / \mathrm{H}_{2} \mathrm{O}$ features are clearly represented. These characteristic absorptions are related either to abundant evaporitic gypsum and/or clay minerals originating from inclusions or nearby pelite horizons known to be present in this lithological unit.

Scan 1, imaging the south facing cliff of the Nunngarut Peninsula, was directly opposed to the sun during the measurements and is therefore evenly illuminated. In contrast, Scan 2, acquired in the morning and facing the eastern coast of the peninsula, featured high illumination differences, which made a topographic correction crucial for the subsequent mapping process (Figure 4c).

With atmospheric and topographic corrections successfully applied to the hyperspectral datacubes, the datacubes provide the basis for a characterisation of the mineralogical composition of the Mârmorilik Formation carbonates, with relevance for exploration mapping. The identification of different carbonates from hyperspectral data is possible using the position and depth of the carbonate-related vibrational overtone absorption band between 2310 and $2340 \mathrm{~nm}$ [41]. Whereas pure calcite features an absorption around $2340 \mathrm{~nm}$, the absorption band of pure dolomite occurs at $2320 \mathrm{~nm}$. Carbonate-related absorptions at even shorter wavelengths can indicate an occurrence of tremolite together with dolomite. This relationship is confirmed by spectroscopic analysis of representative rock samples from the Mârmorilik Formation (Figure 8a). Elemental and mineralogical composition of the samples are further validated by pXRF (portable X-ray fluorescence) and thin section analysis, respectively (see Rosa et al. [19]; pers. commun. C.A. Partin). From the pXRF results, the respective $\mathrm{Ca} / \mathrm{Mg}$ ratios of four to six measurement spots on each sample were calculated and compared to the classification of limestones and dolomites of Chilingar [42]. Sample \#SLA15 featured high Ca/Mg ratios between $31.2 \pm 0.7$ and $619.3 \pm 13.7$ and would be therefore classified as calcitic limestone. The ratio of sample \#562032 ranged between $2.0 \pm 0.5$ and $5.9 \pm 0.9$, indicating a highly dolomitic limestone or calcareous dolomite. Sample \#562048 ranges between a dolomite and magnesian dolomite with a low $\mathrm{Ca} / \mathrm{Mg}$ ratio between $1.0 \pm 0.1$ and $2.0 \pm 0.1$ [42]. A simple MWL mapping approach hence provides a good means of distiguishing these different carbonate phases in the outcrop (Figure 9). Pelite horizons and noncarbonatitic rocks, which are spectrally characterised by a very weak or 
nonexistent carbonate features, were masked out using a threshold based on the MWL depth of the mapped carbonate feature.

The contact between the upper and lower Mârmorilik Formation is clearly visible on the east-facing slope of Nunngarut, as the lower Mârmorilik Formation is dominated by dolomite interbedded with tremolite-rich horizons [43], whereas the upper Mârmorilik Formation is calcite-dominated. Also, a dolomitisation along faults can be traced.

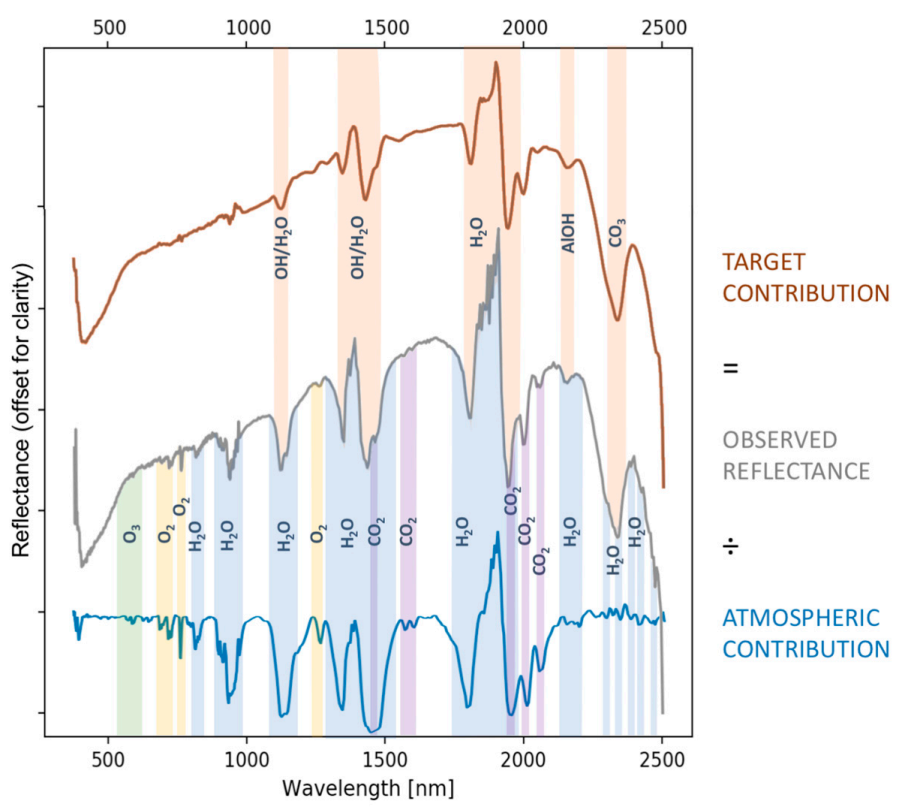

Figure 7. Contribution of geological target and atmosphere to an exemplaric observed reflectance spectrum (Nunngarut study area, Mârmorilik Formation). At this, the target contribution equals the reflectance spectrum after atmospheric correction.

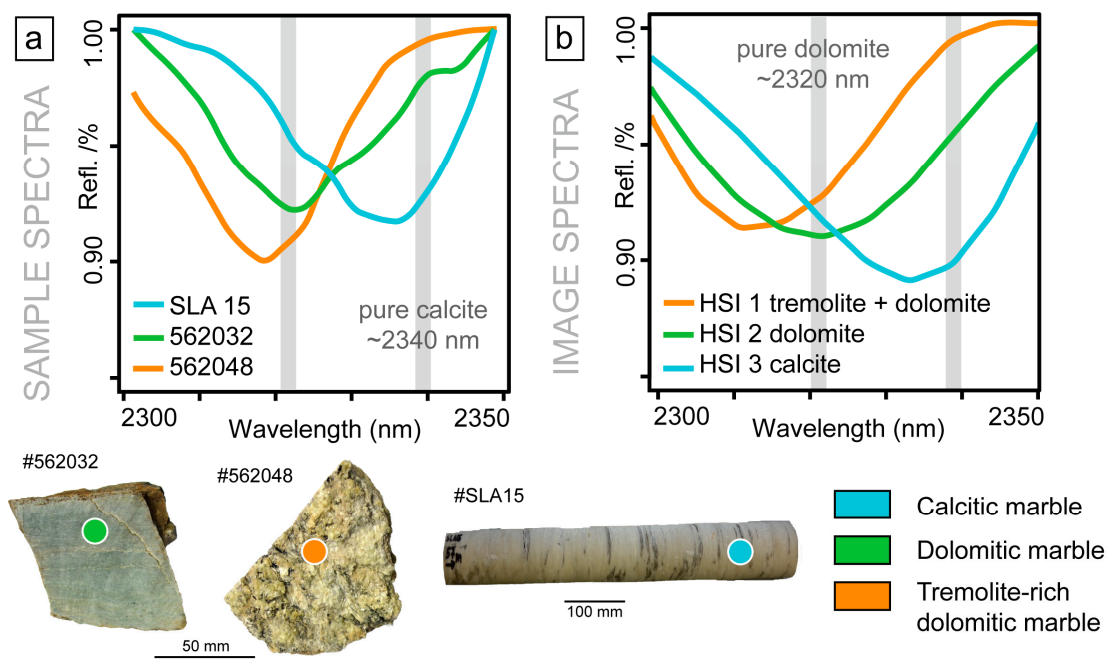

Figure 8. Spectral validation of the Minimum-Wavelength-Position-based mapping of the carbonate composition at Nunngarut test site. (a) Lab point spectra of three carbonate samples of the Maarmorilik formation, representing typical calcitic, dolomitic, and tremolite-rich dolomitic end members; (b) HSI spectral plot of the sampling positions marked in Figure 9, representing calcite-, dolomite-, and tremolite-rich dolomitic end members of the scene. A continuum removal was applied on all spectra. Elemental and mineralogical composition is further validated by portable XRF (pXRF) and thin section analysis, respectively (see Rosa et al. [19]). 


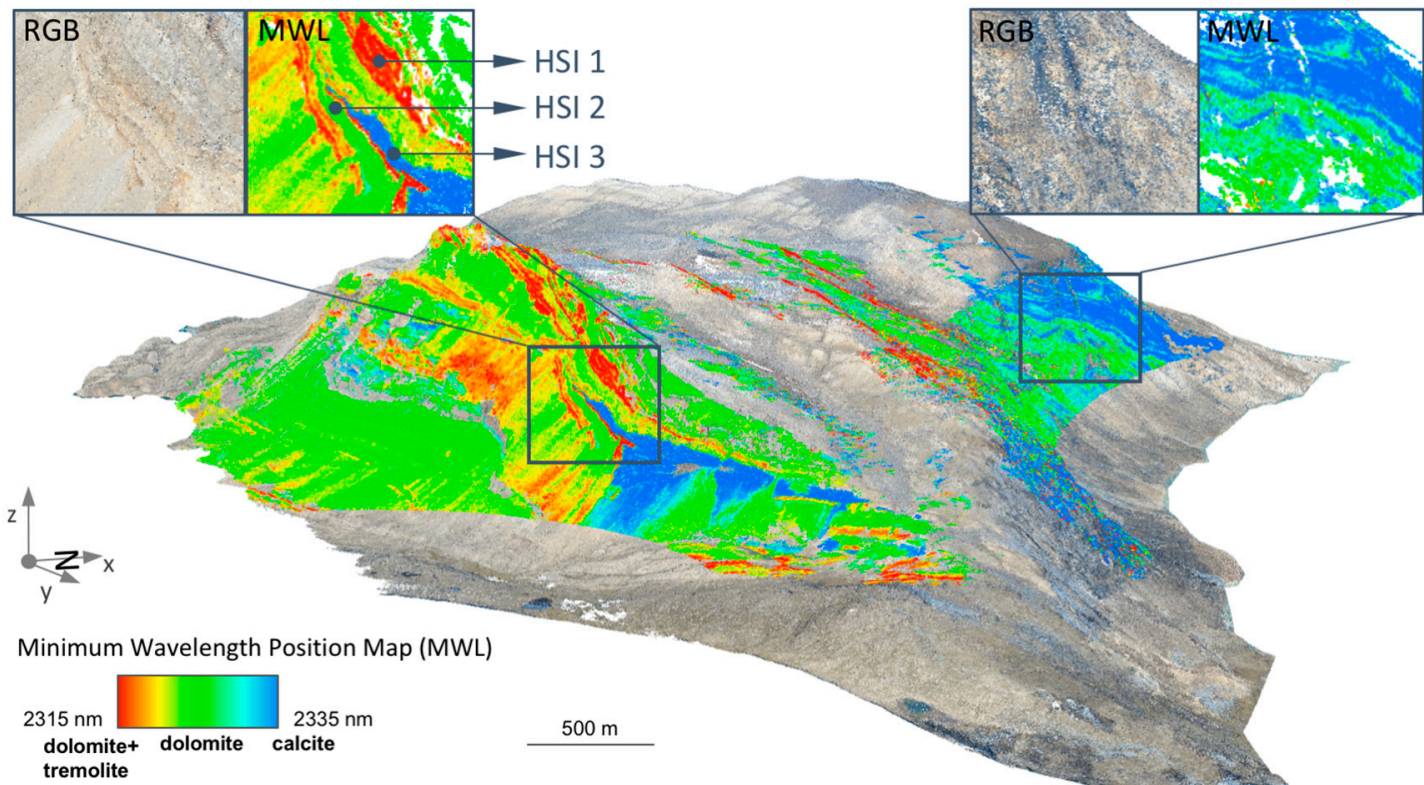

Figure 9. 3D hypercloud of two individual HSI image scenes overlain on photogrammetric RGB point cloud of the Maarmorillik marble cliffs. Minimum Wavelength Position Mapping was applied to both HSI datacubes to highlight variations in carbonate composition. HSI 1, 2, and 3 mark the sampling points of Figure 8.

\subsection{Corta Atalaya, Riotinto, Spain}

For the Corta Atalaya, three overlapping hyperspectral scans are used to demonstrate the described workflow (Figure 1b). The scans were acquired from the same panorama viewpoint of Corta Atalaya, but at different times: Scan 1 was acquired in March 2016, and Scans 2 and 3 were acquired in October 2016. The distance between sensor and target ranges broadly between 400 and $1100 \mathrm{~m}$. The conditions on both acquisition days were dry and sunny, with a very good and constant illumination of the imaged pit wall. Despite the shorter distance to the target compared with that at Nunngarut test site and the Mediterranean climate conditions, i.e., with hot and dry summers, distinct atmospheric absorption features were observed in the image data.

All scans were atmospherically corrected and geometrically rectified using the photogrammetric pointcloud. A topographic correction was attempted but deemed unnecessary in the end, because the geologically most interesting northern and eastern part of the outcrop are evenly illuminated, and the shaded southern wall of the pit does not contain sufficient spectral information. After preprocessing and correction of the scenes, a Minimum Wavelength Position Mapping of the $\mathrm{AlOH}$ feature between 2190 and $2215 \mathrm{~nm}$ was conducted on all three scenes, to exemplarily show the capability of the corrected datasets for alteration mapping. The subsequently created hyperclouds show a great coincidence in the mapped alteration zones and could be easily merged into one final Hypercloud $\mathrm{AlOH}$ map (Figure 10).

The spectral validation of the mapping result was conducted using a set of field spectrometer data acquired in situ. Due to the restricted accessibility of the mine pit, the spectral readings are limited to a few pit levels. However, a wide range of lithologies could be covered and compared to the respective HSI pixel spectrum. A selection is shown in Figure 11a and proves the similarity of spectral shape and the occurrence of spectral features between image and field spectra. The given field sample density allows also us to validate the $\mathrm{AlOH}$ MWL position distribution. In Figure 11b, the $\mathrm{AlOH}$ feature position of each field spectrometer measurement within the main region of interest is displayed as coloured squares using the same colour scale as the underlying HSI mapping result. 


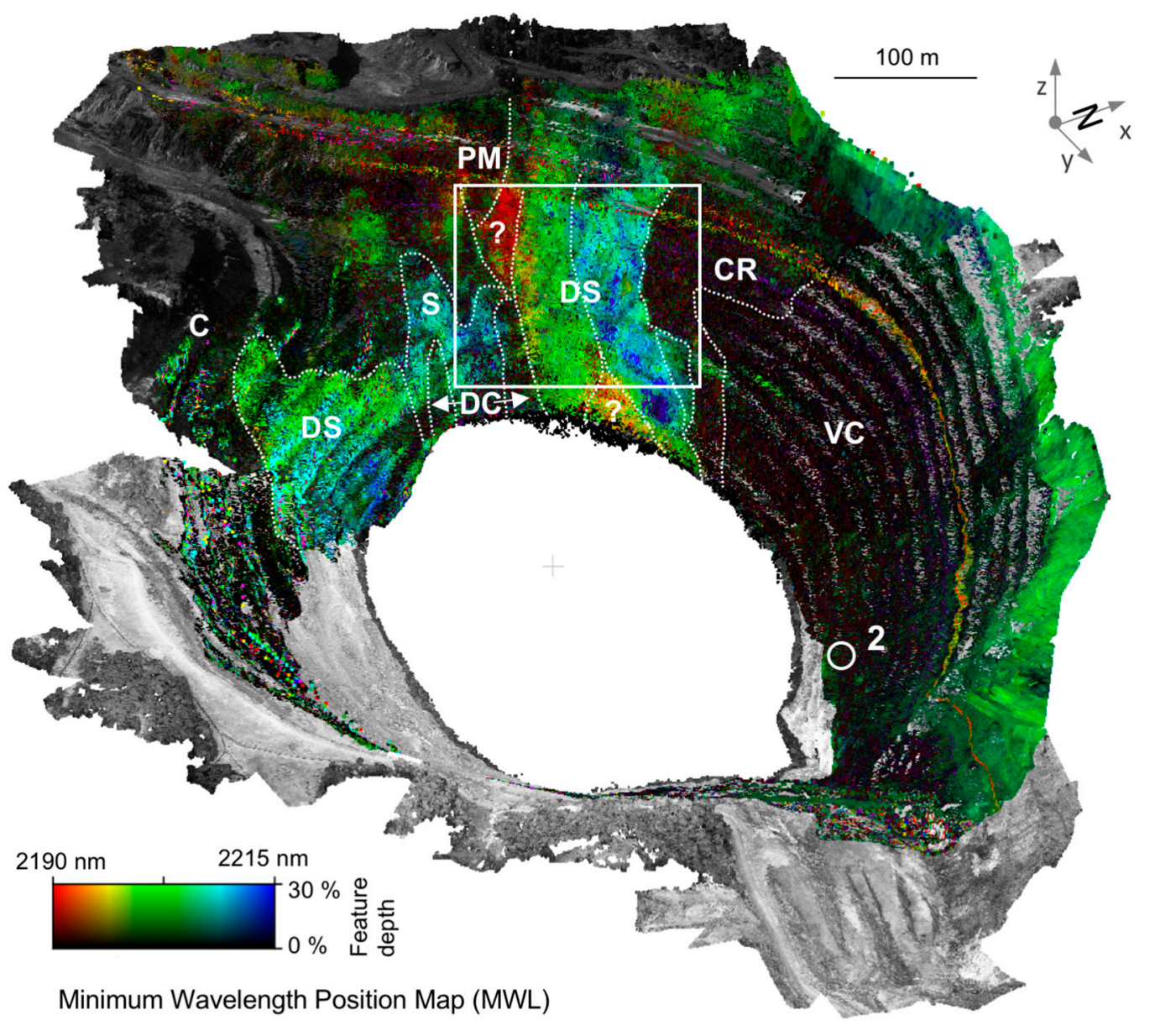

\section{Main lithologies and alteration zones after Sáez \& Donaire 2008:}

\section{Dacites with chloritic alteration \\ DS Dacites with sericitic alteration \\ VC (Sub-)volcanics with chloritic alteration}

CR Conglomerates

$S$ Massive sulfides

PM Pink shales/ Pizarras Moradas

Figure 10. 3D hypercloud display of three individual HSI image scenes overlain on photogrammetric RGB point cloud of the Corta Atalaya open pit. All three scenes were used for Minimum Wavelength Position Mapping to highlight lithological variations associated with differences in the abundance of AlOH-bearing minerals. The white rectangle marks the area shown in Figure 11. The colour differences in the MWL hypercloud show excellent correlation with the known main lithologies and alteration zones [28]. Zones not described in [28] are indicated with question marks. Sample locations for Figure $11 \mathrm{~b}$ are marked with white circles and numbers. 


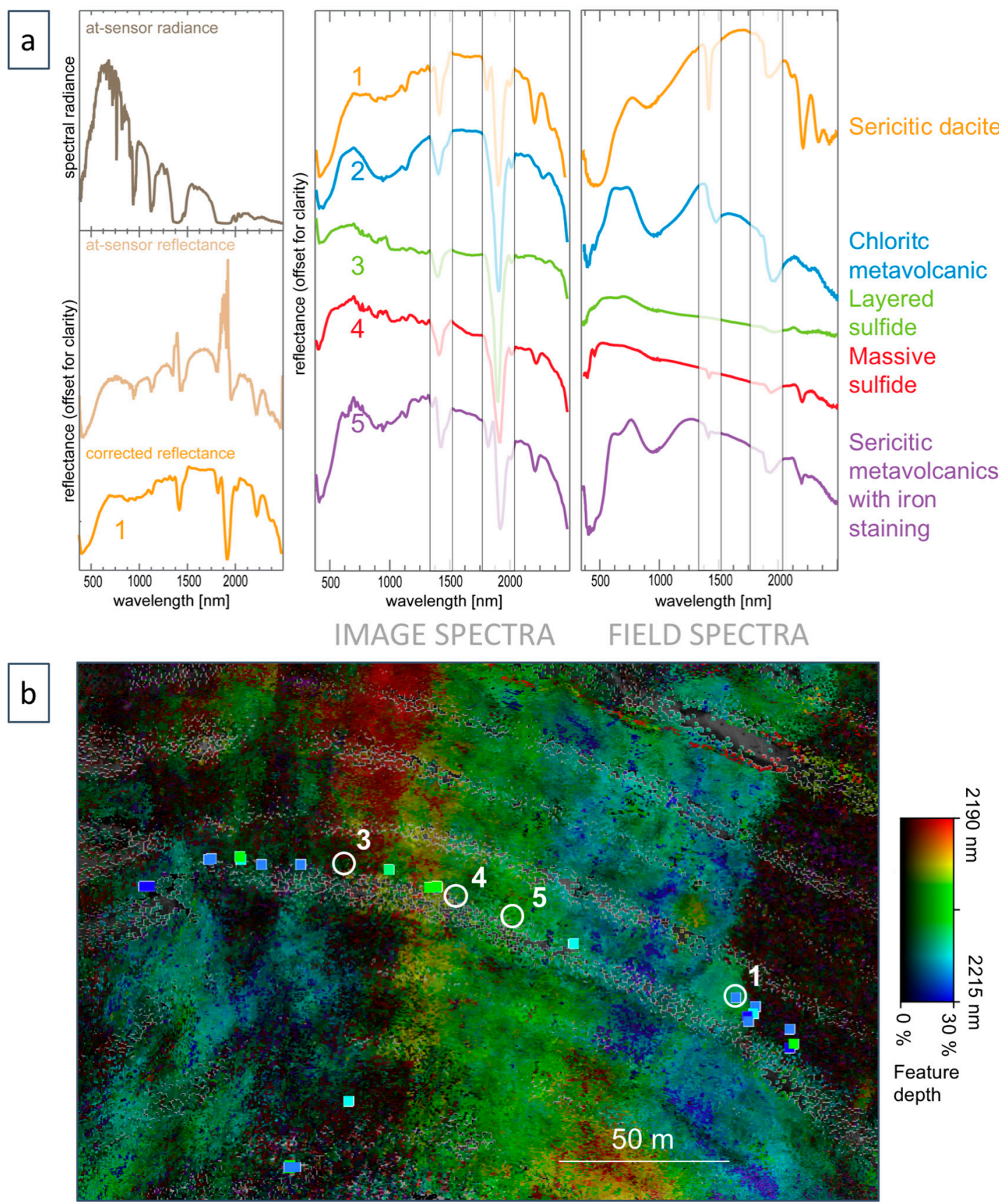

Figure 11. Validation of HSI data of the Corta Atalaya open pit. (a) Left: Spectral signature improvement of Sample Point 1 within different processing stages. Right: Comparison of spectral shape between field spectra and image spectra of the approximate same location. Sample locations are marked with white circles and numbers in Figures 10 and 11b; (b) Comparison of feature position: minimum wavelength map for $\mathrm{AlOH}$ (see map extent in Figure 10) and feature position of field spectra (coloured squares; same colouring scheme).

\section{Discussion}

\subsection{Radiometric and Atmospheric Correction}

Both test scenarios contain spectral distortions due to atmospheric absorption features. At Corta Atalaya/Spain, most of the observed atmospheric absorption features could originate both from upwelling water vapour of the pit lake and from dust and particles caused by the nearby mining 
activities in the adjacent Cerro Colorado open pit. This assumption is supported by the distribution of the atmospherically disturbed image pixels, which are not directly related to the distance of target and sensor, but mainly occur in areas where the signal needed to pass over the water surface in the mining pit. In contrast, for the Greenland site, the intensity of the atmospheric absorptions was roughly proportional to the distance between sensor and target. Here, contributions both from general air humidity and from upwelling water vapour from the fjords separating Nunngarut Peninsula and the respective observation positions on adjacent cliffs can be assumed. The overall atmospheric influence on the signal was much higher than that at Corta Atalaya, which may be related to both the distinctly increased distance to the target and the generally higher air humidity of the arctic climate. The described novel atmospheric correction workflow takes into account this variability in the composition of the atmospheric layer between sensor and target by extracting the shape of the correction curve directly from the scene and determining the correction intensity according to the pixel-specific atmospheric absorption depth and not the distance to the target.

For all five processed datasets, the atmospheric correction approach was fast and robust. Atmospheric absorptions were removed, whereas the general spectral shape and smaller mineral-related features were maintained. It was shown that the correction approach respects all abundant atmospheric components that contribute to the extracted pervasive signal and which we attribute to atmospheric perturbations. Besides water vapour, this may comprise any abundant atmospheric gases (such as $\mathrm{CO}_{2}$ or $\mathrm{O}_{3}$ ) and minor or pervasive amounts of atmospheric dust that show significant spectral absorption features in the VNIR and SWIR. Only in the rare case of an extreme amount of locally concentrated atmospheric dust or gas, e.g., due to blasting or the exhaust of waste gases within a mine, may the atmospheric correction fail for the affected image region. In this case, the local atmospheric perturbations will deviate distinctly from the used correction spectrum and cause an unsatisfactory spectral result. However, such scenarios can be avoided easily by the respective timing of the image acquisition, e.g., ahead of scheduled blasting operations.

It should be noted that for highly distorted pixels, spectral noise can remain at the former atmospheric absorption positions. The affected pixels mostly originate from extremely distant targets. Here, the proportion of the target signal on the spectral signal received at the sensor is so low that a removal of the atmospheric influence leads to an extremely low signal-to-noise ratio of the returned spectrum, which therefore appears noisy and featureless. This may suggest an upper distance limit for long-range HSI. However, this limit would be at an up to ten or more kilometre distance, depending on the atmospheric conditions of the scene. At this distance, the resulting pixel footprint on the ground would be in the range of several hundred square meters, questioning the informative value of the measurement. In conclusion, we were able to prove the successful application of the introduced atmospheric correction approach within a reasonable imaging distance.

\subsection{Topographic Correction}

As shown in the example of Nunngarut Peninsula in Figure 4, topographic correction is necessary under certain circumstances, as it ensures the comparability of absorption intensities between differently illuminated parts of the image. However, whereas the correction is effective for the adjustment of intensity changes, it cannot reconstruct spectral features in poorly illuminated areas of the image with associated low signal intensity, SNR, and feature detail. Therefore, we recommend a masking or at least careful interpretation of extremely poorly illuminated or deeply shadowed image parts. We further suggest evaluating the usefulness of a topographic correction for each imaged scene. From our general experience and the specific performance of the shown examples, natural targets such as mountain slopes or cliffs often have a smoother topography and therefore more consistent illumination than manmade outcrops like quarries and open pit mines. In natural targets, with the resulting smoother transitions between image parts with maximum and minimum illumination, respectively, the topographic correction usually performs well. Artificial targets often feature a terraced geometry and/or rough edges due to blasting and excavation, which generates large illumination 
differences. A topographic correction will not necessarily give an improvement of the image, as the applied corrections in the well-illuminated parts are minor, while the correction of the dark parts may be futile due to the mentioned reasons.

The c-factor method, despite its good performance for topographic correction, needs to be applied carefully. Due to the bandwise calculation of the correction factor using a linear regression, extreme or infinite values in one or several bands can cause an exaggeration of the correction factor for those bands and, finally, a change in the spectral shape. These peak values can be caused by bad pixels in the HSI sensor, which, due to the push-broom character of the camera, form bad pixel lines that are restricted to few adjacent bands. If a topographic correction needs to be applied, a correction or masking of those bad lines is inevitably required for a reliable image result.

\subsection{Validation}

The spectral validation using field spectrometer data demonstrated a great accuracy of both spectral shape and feature position of the corrected image spectra. In general, the difference between the interpolated minimum wavelength of field spectra and the corresponding library spectra for a certain absorption feature was below $5 \mathrm{~nm}$ in both areas of investigation. This value represents the band sampling distance of the SWIR data and lies below the achievable spectral resolution of $12 \mathrm{~nm}$ (FWHM). Locally, higher errors between some image and validation spectra points were observed, but these may be related to the large difference in spatial footprints of the different instruments. The field spectrometer data were retrieved from one or several $8 \mathrm{~mm}$ spots of a single lithologically representative sample, whereas the respective HSI pixel can easily represent a mixture of an area of some square meters of outcrop, depending on the distance to the sensor. Local variability in alteration can affect the representability of the spectrometer reading and lead to deviations from the recorded image spectrum at the same location. Additional to the spectral variations, slight mislocation of the spectrometer readings, which can be caused by the limited accuracy of the sample GPS position that can reach up to $5 \mathrm{~m}$, needs to be taken into account.

\subsection{D Integration}

The potential, the spatial accuracy, and a possible application of the HSI integration with photogrammetric point clouds is discussed in more detail in Salehi et al. [20]. The current paper confirms not only the successful 3D integration for two additional examples, but further proves the capability of the workflow to integrate and merge hyperspectral datasets from different camera locations and viewing angles as well as different acquisition dates and times by eliminating the effects of topography, different illumination conditions, and atmospheric absorptions. This allows the use of hyperspectral data in a new way, as it facilitates the evaluation of spatial relationships between hyperspectral results that are not visible from one observation point or displayable in one dataset, such as opposing faces of a mountain or a mining pit.

\section{Conclusions}

With this paper, we present a novel approach for the atmospheric and topographic correction of long-range ground-based hyperspectral imagery. Such corrections are essential for obtaining reliable information on mineral composition in geological applications. The general workflow is partly based on the algorithms developed for drone-borne and vessel-based HSI data, which were presented and used in our previous papers $[7,20]$, but is adapted and extended by adding radiometric and topographic correction approaches to meet the particular challenges of long-range, ground-based HSI.

The most important outcomes of this paper are the following:

1. The correction spectrum for the atmospheric correction is derived directly from the scene, and the correction intensity is determined according to the pixel-specific atmospheric absorption 
depth. As a result, the workflow is independent from knowledge about the composition of the atmospheric layer or the distance to the target.

2. The incidence angles for the topographic corrections are calculated using the point normals of the photogrammetric 3D outcrop model. This allows us, for the first time, to utilise common topographic correction algorithms, such as the used c-factor method, for vertical outcrops.

3. The generation of a hypercloud, i.e., a geometrically and spectrally accurate combination of a photogrammetric point cloud and the HSI datacube, is achieved through the projective transformations of a photogrammetric 3D outcrop model. The removal of the effects of atmosphere and topography allows the integration of hyperspectral mapping results originating from different camera positions, dates, and, therefore, varying illumination conditions.

4. Two study areas with five HSI datasets in total proved the applicability and robustness of the workflow in differently challenging measuring conditions regarding climate, distance, atmospheric composition, geological diversity, and mapping objectives. A successful MWL mapping demonstrated both the geological applicability and the accuracy of spectral absorption positions and depths.

5. The accuracy and reliability of the created data and mapping results is validated by field spectra and the mineralogical analysis of geological samples.

6. The presented workflow is fast and simple and requires only a minimum of input parameters. Most of the processing steps are automatised and need no or extremely few manual actions.

7. The workflow enables (i) reliable spectral mapping of vertical and completely inaccessible outcrops; (ii) three-dimensional integration of multiple scans and other data sources; and (iii) a higher spectral resolution, range, and SNR than most drone- or air-borne HSI data.

On account of the promising quality of the presented datasets, we highly encourage the use of carefully processed and corrected long-range ground-based HSI data for geological applications and suggest a further development of highly adapted topographic and atmospheric correction algorithms. In several upcoming application-based papers, we will further present and discuss the geological interpretation of data corrected with the presented workflow and their integration with other data types such as structural data and long-wave infrared (LWIR) hyperspectral data.

Acknowledgments: The Helmholtz Institute Freiberg for Resource Technology is gratefully thanked for supporting and funding this project. The authors thank the entire group of "Exploration Technology" for their constructive feedback and extensive testing of the scripts. Further, we thank Atalaya Mining for access to Riotinto mine and IPH Ingeniería y proyectos for performing the UAS flight in Corta Atalaya. The Ministry for Mineral Resources, Government of Greenland, and the Geological Survey of Denmark and Greenland are gratefully acknowledged for funding and supporting fieldwork and data acquisition within the project "Karrat Zinc".

Author Contributions: S.L. developed the processing workflow with substantial contributions from S.S., M.K., and R.G. and implemented the workflow in Python. R.Z. and E.V.S. delivered logistic support in the field and were responsible for data acquisition and photogrammetric processing. S.L., R.Z., and G.U. processed the hyperspectral datasets and performed the geological interpretation and validation. S.L. wrote the manuscript with input from all authors. R.G. supervised the study at all stages.

Conflicts of Interest: The authors declare no conflict of interest.

\section{References}

1. Hubbard, B.E.; Crowley, C.K.; Zimbelman, D.R. Comparative alteration mineral mapping using visible to shortwave infrared (0.4-2.4 mm) Hyperion, ALI, and ASTER imagery. IEEE Trans. Geosci. Remote Sens. 2003, 41, 1401-1410. [CrossRef]

2. Kruse, F.A. Mineral mapping with AVIRIS and EO-1 Hyperion. In Proceedings of the 12th JPL Airborne Geoscience Workshop; Pasadena, CA, USA, 24-28 January 2003, Jet Propulsion Laboratory: Pasadena, CA, USA, 2003; Volume 41, pp. 149-156.

3. Bedini, E. Mapping lithology of the Sarfartoq carbonatite complex, southern West Greenland, using HyMap imaging spectrometer data. Remote Sens. Environ. 2009, 113, 1208-1219. [CrossRef] 
4. Laukamp, C.; Cudahy, T.; Thomas, M.; Jones, M.; Cleverley, J.S.; Oliver, N.H. Hydrothermal mineral alteration patterns in the Mount Isa Inlier revealed by airborne hyperspectral data. Aust. J. Earth Sci. 2011, 58, 917-936. [CrossRef]

5. Zimmermann, R.; Brandmeier, M.; Andreani, L.; Mhopjeni, K.; Gloaguen, R. Remote Sensing Exploration of $\mathrm{Nb}$-Ta-LREE-Enriched Carbonatite (Epembe/Namibia). Remote Sens. 2016, 8, 620. [CrossRef]

6. Jakob, S.; Gloaguen, R.; Laukamp, C. Remote Sensing-Based Exploration of Structurally-Related Mineralizations around Mount Isa, Queensland, Australia. Remote Sens. 2016, 8, 358. [CrossRef]

7. Jakob, S.; Zimmermann, R.; Gloaguen, R. The Need for Accurate Geometric and Radiometric Corrections of Drone-Borne Hyperspectral Data for Mineral Exploration: MEPHySTo-A Toolbox for Pre-Processing Drone-Borne Hyperspectral Data. Remote Sens. 2017, 9, 88. [CrossRef]

8. Gao, B.-C.; Heidebrecht, K.B.; Goetz, A.F.H. Derivation of scaled surface reflectances from AVIRIS data. Remote Sens. Environ. 1993, 44, 165-178. [CrossRef]

9. Adler-Golden, S.M.; Matthew, W.M.; Bernstein, L.S.; Levine, R.Y.; Berk, A.; Richtsmeier, S.C.; Acharya, P.K.; Anderson, G.P.; Felde, J.W.; Gardner, J.A.; et al. Atmospheric correction for shortwave spectral imagery based on MODTRAN4. In Summaries of the Eighth JPL Airborne Earth Science Workshop; Jet Propulsion Laboratory: Pasadena, CA, USA, 1999; Volume 99-17, pp. 21-29.

10. Richter, R.; Schlaepfer, D. Geo-atmospheric processing of airborne imaging spectrometry data, Part 2: Atmospheric/topographic correction. Int. J. Remote Sens. 2002, 23, 2631-2649. [CrossRef]

11. Smith, G.M.; Milton, E.J. The use of the empirical line method to calibrate remotely sensed data to reflectance. Int. J. Remote Sens. 1999, 20, 2653-2662. [CrossRef]

12. Roberts, D.A.; Yamaguchi, Y.; Lyon, R. Comparison of various techniques for calibration of AIS data. In Proceedings of the 2nd Airborne Imaging Spectrometer Data Analysis Workshop; Pasadena, CA, USA, 6-8 May 1986; Jet Propulsion Laboratory: Pasadena, CA, USA, 1986; Volume 86-35, pp. 21-30.

13. Chavez, P.S. An improved dark-object subtraction technique for atmospheric scattering correction of multispectral data. Remote Sens. Environ. 1988, 24, 459-479. [CrossRef]

14. Clark, R.N.; Swayze, G.A.; Livo, K.E.; Kokaly, R.F.; King, T.V.V.; Dalton, J.B.; Vance, J.S.; Rockwell, B.W.; Hoefen, T.; McDougal, R.R. Surface Reflectance Calibration of Terrestrial Imaging Spectroscopy Data: A Tutorial Using AVIRIS. In Proceedings of the 10th Airborne Earth Science Workshop; Jet Propulsion Laboratory: Pasadena, CA, USA, 2002; Volume 02-1.

15. Laliberte, A.S.; Goforth, M.A.; Steele, C.M.; Rango, A. Multispectral remote sensing from unmanned aircraft: Image processing workflows and applications for rangeland environments. Remote Sens. 2011, 3, 2529-2551. [CrossRef]

16. Kurz, T.H.; Buckley, S.J.; Howell, J.A. Close-range hyperspectral imaging for geological field studies: Workflow and methods. Int. J. Remote Sens. 2013, 34, 1798-1822. [CrossRef]

17. Kurz, T.H.; Buckley, S.J. A review of hyperspectral imaging in close range applications. Int. Arch. Photogramm. Remote Sens. Spat. Inf. Sci. 2016, 41, 865-870. [CrossRef]

18. Murphy, R.J.; Taylor, Z.; Schneider, S.; Nieto, J. Mapping clay minerals in an open-pit mine using hyperspectral and LiDAR data. Eur. J. Remote Sens. 2015, 48, 511-526. [CrossRef]

19. Rosa, D.; Dewolfe, M.; Guarnieri, P.; Kolb, J.; Laflamme, C.; Partin, C.A.; Salehi, S.; Sørensen, E.V.; Thaarup, S.; Thrane, K.; et al. Architecture and Mineral Potential of the Paleoproterozoic Karrat Group, West Greenland: Results of the 2016 Season; GEUS Rapport 2017/5; Geological Survey of Denmark and Greenland: Copenhagen, Denmark, 2017; p. 112.

20. Salehi, S.; Lorenz, S.; Sørensen, E.V.; Zimmermann, R.; Fensholt, R.; Heincke, B.H.; Kirsch, M.; Gloaguen, R. Integration of Vessel-Based Hyperspectral Scanning and 3D-Photogrammetry for Mobile Mapping of Steep Coastal Cliffs in the Arctic. Remote Sens. 2008, 10, 175. [CrossRef]

21. Kolb, J.; Keiding, J.K.; Steenfeld, A.; Secher, K.; Keulen, N.; Rosa, D.; Stensgaard, B. M Metallogeny of Greenland. Ore Geol. Rev. 2016, 78, 493-555. [CrossRef]

22. Sørensen, L.L.; Stensgaard, B.M.; Thrane, K.; Rosa, D.; Kalvig, P. Sediment-Hosted Zinc Potential in Greenland; GEUS Rapport 2013/56; Geological Survey of Denmark and Greenland: Copenhagen, Denmark, 2013; p. 184.

23. Grocott, J.; McCaffrey, K.J.W. Basin evolution and destruction in an Early Proterozoic continental margin: The Rinkian fold-thrust belt of central West Greenland. J. Geol. Soc. 2017, 174, 453-467. [CrossRef]

24. Pedersen, F.D. Remobilization of the massive sulfide ore of the Black Angel Mine, central West Greenland. Econ. Geol. 1980, 75, 1022-1041. [CrossRef] 
25. Henderson, G.; Pulvertaft, T.C.R. Geological Map of Greenland, 1:100 000. Mârmorilik 71 V.2 Syd, Nûgâtsiaq 71 V.2 Nord, Pangnertôq 72 V.2 Syd. Lithostratigraphy and Structure of a Lower Proterozoic Dome and Nappe Complex; Geological Survey of Greenland: Copenhagen, Denmark, 1987; p. 72.

26. Guarnieri, P.; Partin, C.; Rosa, D. Palaeovalleys at the Basal Unconformity of the Palaeoproterozoic Karrat Group, West Greenland; Geological Survey of Denmark and Greenland Bulletin; Geological Survey of Denmark and Greenland: Copenhagen, Denmark, 2016; pp. 63-66.

27. Rosa, D.; Guarnieri, P.; Hollis, J.; Kolb, J.; Partin, C.A.; Petersen, J.; Sørensen, E.V.; Thomassen, B.; Thomsen, L.; Thrane, K. Architecture and Mineral Potential of the Paleoproterozoic Karrat Group, West Greenland: Results of the 2015 Season; Geological Survey of Denmark and Greenland: Copenhagen, Denmark, 2016; p. 98.

28. Sáez, R.; Donaire, T. Corta atalaya. In Geología de Huelva: Lugares de Interés Geológico; Universidad de Huelva, Facultad de Ciencias Experimentales: Huelva, Spain, 2008; pp. 106-111.

29. Soriano, C.; Casas, J. Variscan tectonics in the Iberian Pyrite Belt, South Portuguese Zone. Int. J. Earth Sci. 2002, 91, 882-896. [CrossRef]

30. Green, A.A.; Berman, M.; Switzer, P.; Craig, M.D. A transformation for ordering multispectral data in terms of image quality with implications for noise removal. IEEE Trans. Geosci. Remote Sens. 1988, 26, 65-74. [CrossRef]

31. Phillips, R.D.; Blinn, C.E.; Watson, L.T.; Wynne, R.H. An Adaptive Noise-Filtering Algorithm for AVIRIS Data with Implications for Classification Accuracy. IEEE Trans. Geosci. Remote Sens. 2009, 47, 3168-3179. [CrossRef]

32. Westoby, M.J.; Brasington, J.; Glasser, N.F.; Hambrey, M.J.; Reynolds, J.M. 'Structure-from-Motion' photogrammetry: A low-cost, effective tool for geoscience applications. Geomorphology 2012, 179, 300-314. [CrossRef]

33. Eltner, A.; Kaiser, A.; Castillo, C.; Rock, G.; Neugirg, F.; Abellán, A. Image-based surface reconstruction in geomorphometry-Merits, limits and developments. Earth Surf. Dyn. 2016, 4, 359-389. [CrossRef]

34. Carrivick, J.L.; Smith, M.W.; Quincey, D.J. Structure from Motion in the Geosciences; John Wiley \& Sons, Ltd.: Chichester, UK, 2016; ISBN 978-1-118-89581-8.

35. James, M.R.; Robson, S.; d'Oleire-Oltmanns, S.; Niethammer, U. Optimising UAV topographic surveys processed with structure-from-motion: Ground control quality, quantity and bundle adjustment. Geomorphology 2017, 280, 51-66. [CrossRef]

36. Lowe, D.G. Object recognition from local scale-invariant features. In Proceedings of the International Conference on Computer Vision, Kerkyra, Greece, 20-27 September 1999; Volume 2, pp. 1150-1157.

37. Muja, M.; Lowe, D. Fast approximate nearest neighbors with automatic algorithm configuration. In Proceedings of the Fourth International Conference on Computer Vision Theory and Applications, Lisboa, Portugal, 5-8 February 2009; Volume 1, pp. 1-10.

38. Teillet, P.M.; Guindon, B.; Goodenough, D.G. On the Slope-Aspect Correction of Multispectral Scanner Data. Can. J. Remote Sens. 1982, 8, 84-106. [CrossRef]

39. Bakker, W.H.; van Ruitenbeek, F.J.A.; van der Werff, H.M.A. Hyperspectral image mapping by automatic color coding of absorption features. In Proceedings of the 7th EARSEL Workshop of the Special Interest Group in Imaging Spectroscopy, Edinburgh, UK, 11-13 April 2011; pp. 56-57.

40. van der Meer, F.; Kopačková, V.; Koucká, L.; van der Werff, H.M.A.; van Ruitenbeek, F.J.A.; Bakker, W.H. Wavelength feature mapping as a proxy to mineral chemistry for investigating geologic systems: An example from the Rodalquilar epithermal system. Int. J. Appl. Earth Obs. Geoinf. 2018, 64, 237-248. [CrossRef]

41. Gaffey, S.J. Reflectance spectroscopy in the visible and near-infrared $(0.35-2.55 \mu \mathrm{m})$ : Applications in carbonate petrology. Geology 1985, 13, 270-273. [CrossRef]

42. Chilingar, G.V. Classification of Limestones and Dolomites on Basis of Ca/Mg Ratio. SEPM J. Sediment. Res. 1957, 27, 187-189. [CrossRef]

43. Garde, A.A. The Lower Proterozoic Marmorilik Formation, East of Mârmorilik, West Greenland; Nyt Nordisk Forlag Arnold Busck: Copenhagen, Denmark, 1978; Volume 200, ISBN 978-87-17-02525-7.

(C) 2018 by the authors. Licensee MDPI, Basel, Switzerland. This article is an open access article distributed under the terms and conditions of the Creative Commons Attribution (CC BY) license (http://creativecommons.org/licenses/by/4.0/). 